Check for updates

Cite this: RSC Adv., 2018, 8, 9261

Received 11th December 2017 Accepted 24th February 2018

DOI: $10.1039 / c 7 r a 13228 j$

rsc.li/rsc-advances

\section{Preparation and characterization of polyamide 6 fibre based on a phosphorus-containing flame retardant $\uparrow$}

\begin{abstract}
Ke Liu, Yuanyuan Li, Lei Tao and Ru Xiao (D) *
Intrinsically flame retardant polyamide 6 (FRPA6) was synthesized by melt polycondensation of caprolactam and 9,10-dihydro-10-[2,3-di(hydroxycarbonyl)propyl]-10-phosphaphenanthrene-10-oxide (DDP). Following this, FRPA6 fibres were prepared by melt spinning. The chemical structure, thermal stability, mechanical and combustion properties of FRPA6 were characterized by Fourier transform infrared spectroscopy, nuclear magnetic resonance spectroscopy, differential scanning calorimetry, thermogravimetric analysis, tensile measurements, vertical burning measurements, limiting oxygen index (LOI) measurements, cone calorimetry and scanning electron microscopy. The thermal stability of FRPA6 decreased to a certain extent, but the amount of residual char was improved. FRPA6 containing $5 \mathrm{wt} \%$ DDP could achieve a V0 rating with an LOI value of $33.7 \%$. The spinnability of FRPA6 fibres was good and the tenacity at break reached $3.0 \mathrm{cN}$ dtex ${ }^{-1}$ which met the requirements of textiles. The flame retardancy of FRPA6 fibres was definitely improved and the LOI value of FRPA6-5 fabric could reach $28.4 \%$, thereby showing good prospect in applications.
\end{abstract}

\section{Introduction}

Polyamide 6 (PA6) is one of the most important and extensively used polymeric materials owing to its excellent chemical resistance, high mechanical strength, high abrasion and spinnability. PA6 fibre is the second most produced synthetic fibre and has wide applications. ${ }^{\mathbf{1 - 5}}$ However, similar to most polymers, poor flame retardancy is one of the drawbacks of neat PA6. ${ }^{6}$ To meet the strict fire safety requirements in some fields, such as electrical appliances, and textiles for curtains and carpets which are used at home and on planes, it is necessary to improve the flame retardancy of PA6, especially for PA6 fibres. ${ }^{7-10}$

Intensive studies have been made to improve the flame retardancy of PA6, and much valuable results have been achieved so far. However, most of the studies of flame retardant PA6 (FRPA6) were focused on resin and the research studies discussing on FRPA6 fibres are rare. The preparation of FRPA6 fibres and fabrics is more difficult than that of its resin for two reasons. On the one hand, good flame retardant performance needs a larger amount of flame retardants, but adding a large amount of flame retardants leads to poor spinnability for PA6

State Key Laboratory for Modification of Chemical Fibers and Polymer Materials, College of Materials Science and Engineering, Donghua University, Shanghai 201620, P. R. China. E-mail: xiaoru@dhu.edu.cn; Fax: +86-21-67792826; Tel: +8621-67792826

$\uparrow$ Electronic supplementary information (ESI) available. See DOI: $10.1039 / \mathrm{c} 7 \mathrm{ra} 13228 \mathrm{j}$ fibres. On the other hand, flame retardants are usually introduced to PA6 via melt processing and the flame retardant in the composites is easily exuded by the water due to the larger exposure area of fibre materials which causing the deterioration of flame retardancy. ${ }^{10,11}$ Thus, the flame retardant with high efficiency and persistence is needed for PA6 fibres. Several phosphorus-containing reactive flame retardants have been used to prepare flame retardant polyamide because of their high flame retardant efficiency as well as no release of toxic gases during combustion. ${ }^{\mathbf{1 2 - 1 5}}$ It was reported that the flame retardant polyamide 66 was synthesized by the copolymerization of nylon 66 salt and 2-carboxyethyl phenyl phosphinic acid (CEPPA) and the obtained polyamide 66 had good flame retardancy without any obvious reduction in the mechanical properties. ${ }^{16}$ Yang et al. prepared an intrinsically halogen-free flame retardant polyamide 66 (FR-PA66) by the polymerization of nylon 66 salt and bis(4-carboxyphenyl) phenyl phosphine oxide (BCPPO) as flame retardant. With the introduction of BCPPO, FR-PA66 exhibited an improved thermal stability. The limiting oxygen index (LOI) value of FR-PA66 with $9 \mathrm{wt} \%$ flame retardant reached to $27.2 \%$, and the corresponding vertical burning test (UL94) reached V-0 rating. ${ }^{17}$ Sabyasachi Gaan et al. synthesized and evaluated two bridged 9,10-dihydro-9-oxa-10phosphaphenanthrene-10-oxide (DOPO) derivatives as flame retardant additives in PA6 engineering plastics. The analytical evaluation of FRPA6 indicates a good flame retardant behaviour of both bridged DOPO derivatives, achieving a V-0 rating $(1 \mathrm{~mm})$ in the UL 94 vertical burning test. Additionally, it was found that the bridged DOPO derivatives are primarily active in the gas- 
phase through flame inhibition as well as via increased melt flow-drip flame retardant mechanism. DOPO derivatives could be an attractive flame retardant alternative solution for PA6. ${ }^{18}$ However, only very few research investigations have been reported on the preparation of intrinsically flame retardant polyamide 6 and its fibres.

Recently, 9,10-dihydro-10-[2,3-di(hydroxycarbonyl)propyl]10-phosphaphenanthrene-10-oxide (DDP), a kind of DOPO derivatives, has attracted the attention of researchers due to its high reactivity, high thermal stability and its high flame retardant efficiency. ${ }^{19-21}$ When DDP as monomer was incorporated into polymers, the generated copolymer exhibited good flame retardancy. Chang et al. synthesized a series of flame retardant poly(ethylene terephthalate) (PET) with the introduction of DDP. A higher phosphorus content resulted in lower crystallinity, lower melting temperature, but greater LOI value and higher residual char after thermal degradations. The LOI value of flame retardant PET containing $0.7 \mathrm{wt} \%$ phosphorus could reach to $33.3 \% .^{22,23}$ Chen et al. synthesized a series of flame retardant poly(trimethylene terephthalate) (PTT) with the introduction of DDP. The chemically incorporated DDP to PTT decreased the melt temperature, but increased the LOI value of PTT. The LOI value of PTT containing $10 \mathrm{wt} \%$ DDP could reach to $28.0 \%{ }^{24}$ Ge et al. synthesized polyamide containing DDP via interfacial polymerization. The observed results show that the inherent flame retardant polyamide has good thermal stability and the incorporation of DDP could significantly improve the flame retardancy of polyamide. ${ }^{25}$ However, polyamide used as engineering plastics and fibres mainly prepared by melt polycondensation. Moreover, as compared to interface condensation, the product of melt polycondensation is pure and the process is free from pollution.

To the best of our knowledge, there are no reports on the synthesis of polyamide 6 containing DDP by melt polycondensation. On this context, in this work intrinsically flame retardant polyamide 6 samples were prepared by introducing DDP as a monomer during melt polycondensation of caprolactam. Following this, the fibres were prepared by melt spinning. The chemical structure, thermal property, mechanical property and burning behaviors of PA6 samples have also been investigated.

\section{Experimental}

\subsection{Materials}

Caprolactam monomer was supplied by DSM Nanjing Chemical Co., Ltd. Adipic acid, decamethylene diamine, sulfuric acid, dimethylsulfoxide (DMSO), deuterosulfuric acid, deuterated DMSO and hexafluoroisopropanol (HFIP) were purchased from Sinopharm Chemical Reagent Co., Ltd. (China). DDP was purchased from Eutec Chemical (Shanghai) Co., Ltd. Deionized water was produced in the laboratory and all other materials were used without any further purification.

\subsection{Preparation of flame retardant polyamide 6 fibres}

Before the incorporation for the polycondensation of PA6, the flame retardant required to be reacted with decamethylene diamine in order to get a structure containing amidogen and carboxyl at each end. DDP combines with decamethylene diamine to form a DDP salt solution before added into polymerization (Scheme 1). The DDP salt solution was obtained based on the following procedure with employing a molar ratio of DDP to decamethylene diamine of $1: 1$. At first, the weighed decamethylene diamine and deionized water were added to a three-necked round bottom flask with mechanical stirrer and a reflux condenser at $50{ }^{\circ} \mathrm{C}$. Then, DDP was slowly added to the solution during $30 \mathrm{~min}$ and then it was heated up to $60{ }^{\circ} \mathrm{C}$ for $2 \mathrm{~h}$. At last, the obtained pale yellow DDP salt solution was cooled to room temperature for further use.

FRPA6 was prepared in a GSHA-5L polymerization autoclave which was equipped with a nitrogen inlet and a mechanical stirrer. A typical polymerization route for the preparation of FRPA6 is as follows. ${ }^{26}$ Firstly, the weighed caprolactam, DDP salt solution, adipic acid and deionized water were added into the polymerization autoclave. The air in the reactor was purged completely by nitrogen before the reaction. Then, the autoclave was heated to $250{ }^{\circ} \mathrm{C}$ and the mixture was maintained at this temperature for $3 \mathrm{~h}$ between 0.6 and $0.8 \mathrm{MPa}$. The temperature was then decreased to $240{ }^{\circ} \mathrm{C}$, whereas the pressure was decreased to atm. Pressure, which was kept under nitrogen flow for $5 \mathrm{~h}$ for the purpose of protection. Then the polymerization was kept at $240{ }^{\circ} \mathrm{C}$ under vacuum for $0.5 \mathrm{~h}$. Finally, the product was removed from the reactor, cooled in cold water and cut into slices. In order to remove the unreacted small molecules such as caprolactam, the obtained slices were extracted with boiling water for $24 \mathrm{~h}$ and dried in a vacuum oven at $105^{\circ} \mathrm{C}$ for $24 \mathrm{~h}$. The FRPA6 samples containing 2, 3, 4 and 5 wt $\%$ DDP (labeled as FRPA6-2, FRPA6-3, FRPA6-4 and FRPA6-5 respectively) were then prepared. Before analytical measurements, the synthesized FRPA6 samples were purified by firstly dissolving in sulfuric acid and precipitation in deionized water, then extracted with dimethylsulfoxide for $6 \mathrm{~h}$ and washed with deionized water, repeat the above steps three times and the final product dried in a vacuum oven at $105{ }^{\circ} \mathrm{C}$ for $24 \mathrm{~h}$.

The PA6 and FRPA6 slices were dried at $110^{\circ} \mathrm{C}$ for $48 \mathrm{~h}$ under vacuum before the processing. The fibres were prepared by using an ABE Spinner Instrument (ABE 2 25X5, ABE Corp., Japan) equipped with a spinneret containing 36 orifices, whose diameter was $0.3 \mathrm{~mm}$. Temperature zones 1, 2, 3, 4 and the spinneret in the spinning equipment were maintained at $260^{\circ} \mathrm{C}, 265^{\circ} \mathrm{C}, 260^{\circ} \mathrm{C}, 260^{\circ} \mathrm{C}$ and $260^{\circ} \mathrm{C}$ respectively. The fibres were quenched in the air at room temperature and collected at a take-up velocity of $800 \mathrm{~m} \mathrm{~min}^{-1}$. In the last step, the fibres were drawn by a Barmag 3010 Drawer (BARMAG, Germany) at a draw ratio of 3.5 and at a drawing temperature of $120{ }^{\circ} \mathrm{C}$. In order to further study the flame retardant properties of fibres, knit fabrics of the PA6 and FRPA6 fibres were prepared by KU482A weaving test machine (China), and the area density of the knit fabrics were $340 \mathrm{~g} \mathrm{~m}^{-2}$.

\subsection{Characterization}

Fourier transform infrared (FTIR) spectra were obtained between 600 and $4000 \mathrm{~cm}^{-1}$ at a resolution of $4 \mathrm{~cm}^{-1}$ on 


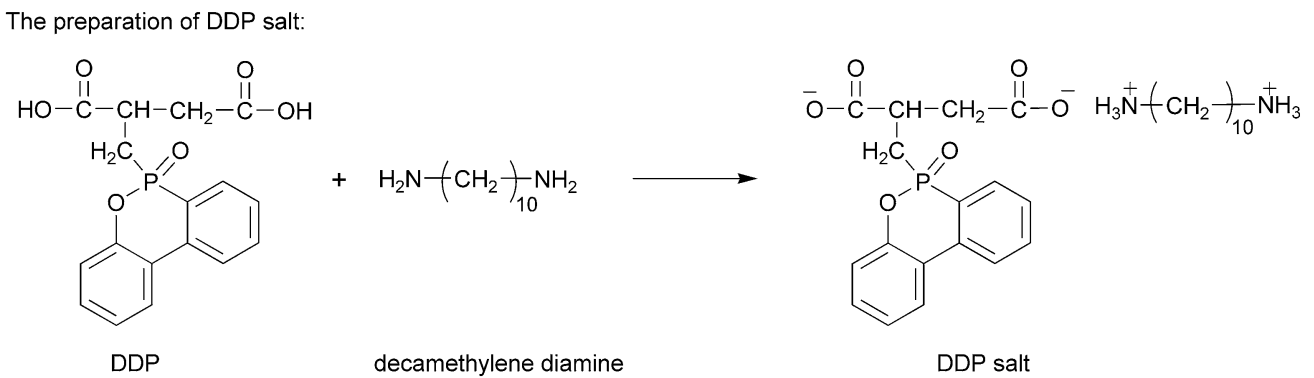

The preparation of FRPA6:
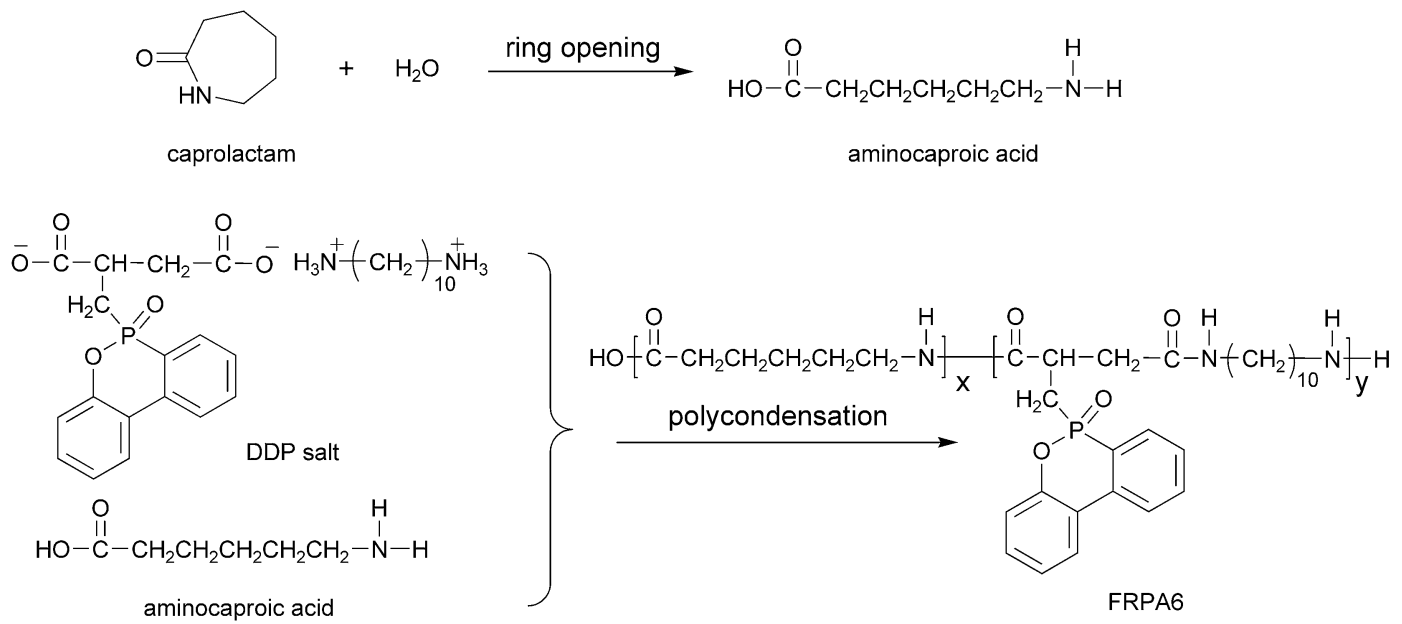

Scheme 1 Preparation process of FRPA6.

a Nicolet 6700 FTIR instrument (USA) equipped with an attenuated total reflection (ATR) cell and a diamond crystal. The proton nuclear magnetic resonance $\left({ }^{1} \mathrm{H}-\mathrm{NMR}\right.$ and $\left.{ }^{31} \mathrm{P}-\mathrm{NMR}\right)$ spectra were obtained using a Bruker Avance $400 \mathrm{MHz}$ NMR (Switzerland). The molecular weight of PA6 and FRPA6 could be expressed through the relative viscosity using the eqn (1), where $M_{\eta}$ refers to the viscosity-average molecular weight and $\eta_{\mathrm{r}}$ refers to the relative viscosity.

$$
M_{\eta}=11500 \times\left(\eta_{\mathrm{r}}-1\right)
$$

Relative viscosity was measured at a concentration of $0.01 \mathrm{~g} \mathrm{~mL}^{-1}$ in sulfuric acid with Ubbelohde viscometer (the inner diameter is approximately $1.0-1.1 \mathrm{~mm}$ ) at $20{ }^{\circ} \mathrm{C} .{ }^{26}$ The relative viscosity of all the samples was measured at least three times and the coefficient of variation (standard deviation/ average) was found to be less than $1 \%$ for the sake of reproducibility. The molecular weight and molecular weight distribution of PA6 and FRPA6 were performed through gel permeation chromatography (GPC) operated by a PL-GPC50 (USA) at $40{ }^{\circ} \mathrm{C}$ with a flow rate of $0.3 \mathrm{~mL} \mathrm{~min}{ }^{-1}$. All the samples were dissolved and analyzed in HFIP at the concentration of $1.0 \mathrm{mg} \mathrm{mL}^{-1}$. Each sample was characterized at least 3 times resulting in an experimental uncertainty of $5 \%$ of the value. Differential scanning calorimetry (DSC) measurements were carried out on a TA Q20 instrument (USA) which was calibrated using the standards. The samples were at first heated from room temperature to $250{ }^{\circ} \mathrm{C}$ at a heating rate of $40{ }^{\circ} \mathrm{C} \mathrm{min}^{-1}$ under nitrogen atmosphere which was maintained for 5 min to erase the previous thermal history, then was cooled down to $100{ }^{\circ} \mathrm{C}$ and reheated to $250{ }^{\circ} \mathrm{C}$ both at a rate of $10^{\circ} \mathrm{C} \min ^{-1}$. The degree of crystallinity $\left(X_{\mathrm{c}}\right)$ was determined by using the following eqn (2):

$$
X_{\mathrm{c}}=\frac{\Delta H_{\mathrm{m}}}{\Delta H_{\mathrm{m}}^{*}} \times 100 \%
$$

where $\Delta H_{\mathrm{m}}$ is the melting enthalpy of PA6 in the sample and $\Delta H_{\mathrm{m}}^{*}$ is the melting enthalpy of fully crystalline PA6, the value of which is $190.6 \mathrm{~J} \mathrm{~g}^{-1}{ }^{27}$ Thermogravimetric analysis (TGA) was conducted using a Netzsch TG 209F1 thermal analyzer (Germany) with a purge flow of $10 \mathrm{~mL} \mathrm{~min}{ }^{-1}$ (nitrogen) for protection purpose, at a heating rate of $15{ }^{\circ} \mathrm{C} \mathrm{min}^{-1}$ from 40 to $700{ }^{\circ} \mathrm{C}$ and a sample purge flow of $20 \mathrm{~mL} \mathrm{~min}^{-1}$ in air atmosphere. All the samples were kept within 5-10 $\mathrm{mg}$ and placed into open alumina crucibles. Vertical burning test of resins was conducted using a M601 instrument (China) with sheet dimensions of $127 \mathrm{~mm} \times 12.7 \mathrm{~mm} \times 3.2 \mathrm{~mm}$ according to ASTM D3801-2010, and vertical burning test of fabrics was conducted with fabric size of $300 \mathrm{~mm} \times 76 \mathrm{~mm}$ according to ASTM D6413. LOI test of resins was measured using a ZR-01 LOI 
apparatus (China) with sheet dimensions of $100 \mathrm{~mm} \times 10 \mathrm{~mm}$ $\times 4 \mathrm{~mm}$, and LOI test of fabrics was measured with fabric size of $140 \mathrm{~mm} \times 52 \mathrm{~mm}$ according to ASTM D2863. Cone calorimeter tests were used to measure the flame retardancy according to ISO 5660-1 using a FTT cone calorimeter (UK). Specimens with a size of $100 \mathrm{~mm} \times 100 \mathrm{~mm} \times 3 \mathrm{~mm}$ were wrapped in an aluminium foil and exposed horizontally to a heat flux of $50 \mathrm{~kW} \mathrm{~m} \mathrm{~m}^{-2}$. Three measurements were recorded for each sample and the mean value was calculated. Scanning electron microscope (SEM) was used to characterize the morphology of samples using JSM-5600LV SEM (JEOL, Japan) with an accelerating voltage of $10 \mathrm{kV}$. The energy dispersive spectroscopy (EDS) analysis of the samples was performed through AZtec X-Max 20 EDS system (Oxford, UK). The mechanical test of samples was carried out using an Instron material testing machine (USA) according to ISO 527-1:2012. The tensile test of PA6 fibres was carried out using a tensile machine (Model XQ-1C, China) with a drawing speed of $40 \mathrm{~mm} \mathrm{~min}^{-1}$ and at a clamping distance of $20 \mathrm{~mm}$. Orientation test was taken using a sound velocity measuring instrument (SOM-II, Donghua University) under a tension of $0.1 \mathrm{~g}$ dtex $^{-1}$ at the speed of sound propagation of $20 \mathrm{~cm}$ and $40 \mathrm{~cm}$ respectively.

\section{Results and discussion}

\subsection{Properties of flame retardant polyamide 6 resin}

3.1.1. Structure analysis. To investigate the structure of DDP salt, FTIR spectra of DDP and DDP salt were obtained which have been shown in Fig. 1. It can be seen from Fig. 1(a) that the typical absorption of DDP appearing at $1710 \mathrm{~cm}^{-1}$ is due to $\mathrm{C}=\mathrm{O}$ stretching vibration of carboxylic acid and the other characteristic peaks observed at $1429 \mathrm{~cm}^{-1}, 1180 \mathrm{~cm}^{-1}$, $915 \mathrm{~cm}^{-1}$ and $758 \mathrm{~cm}^{-1}$ are due to the stretch vibration of $\mathrm{P}-\mathrm{C}$, $\mathrm{P}=\mathrm{O}, \mathrm{P}-\mathrm{O}-\mathrm{Ph}$ and $\mathrm{C}-\mathrm{H}$ of benzene ring respectively. ${ }^{28,29}$ In Fig. 1(b), the band appearing at $1698 \mathrm{~cm}^{-1}$ is due to $\mathrm{C}=\mathrm{O}$ absorption of DDP, the band at $1639 \mathrm{~cm}^{-1}$ is due to $\mathrm{C}=\mathrm{O}$ stretching (Amide I) and the peak at $1558 \mathrm{~cm}^{-1}$ is due to $\mathrm{N}-\mathrm{H}$ deformation and $\mathrm{C}-\mathrm{N}$ stretching (Amide II). The appearance of

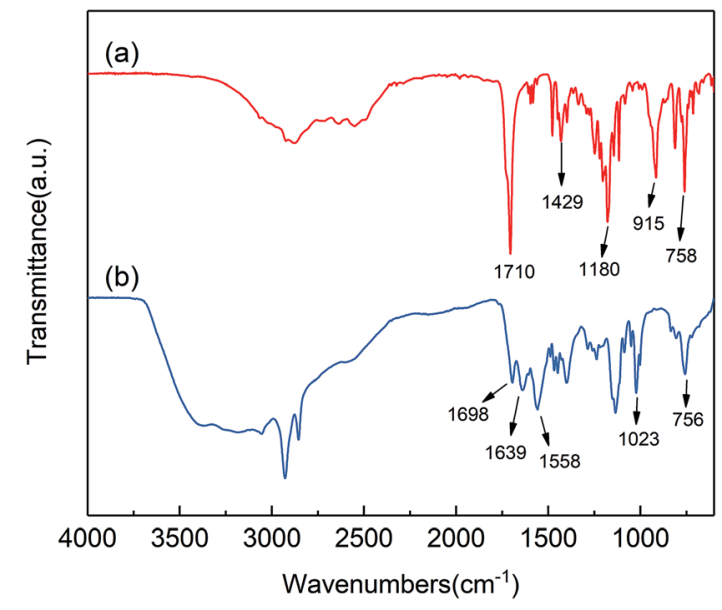

Fig. 1 FTIR spectra of DDP (a) and DDP salt (b).
Amide I and Amide II peaks indicating the formation of DDP salt. For DDP, absorption peak at $915 \mathrm{~cm}^{-1}$ attributed to the stretching vibrations of $\mathrm{P}-\mathrm{O}-\mathrm{C}$. However, by reacting with the decamethylene diamine which has the electron-donating group, electron cloud density of $\mathrm{P}-\mathrm{O}-\mathrm{C}$ in DDP increased and the absorption peak of $\mathrm{P}-\mathrm{O}-\mathrm{C}$ moved to $1023 \mathrm{~cm}^{-1} \cdot{ }^{23,30-32}$

The FTIR spectra of PA6 and FRPA6-5 have been shown in Fig. 2. The absorption peak at $3300 \mathrm{~cm}^{-1}$ is due to the stretching vibration of $\mathrm{N}-\mathrm{H}$, the peaks at $2932 \mathrm{~cm}^{-1}$ and at $2854 \mathrm{~cm}^{-1}$ are due to $-\mathrm{CH}_{2}-$ stretching, the peak at $1640 \mathrm{~cm}^{-1}$ is due to $\mathrm{C}=\mathrm{O}$ stretching (Amide $\mathrm{I}$ ) and the peak at $1540 \mathrm{~cm}^{-1}$ is due to $\mathrm{N}-\mathrm{H}$ deformation and $\mathrm{C}-\mathrm{N}$ stretching (Amide II), the peak at $1465 \mathrm{~cm}^{-1}$ is due to the specific absorption peak of PA6. $^{28,33}$ However, some new absorption peaks were also observed in the spectra of FRPA6. The peak appearing at $1697 \mathrm{~cm}^{-1}$ is corresponding to the $\mathrm{C}=\mathrm{O}$ absorption band of DDP, the peak at $1436 \mathrm{~cm}^{-1}$ is due to the $\mathrm{P}-\mathrm{CH}_{2}-$ stretching vibration, the peak appearing at $1236 \mathrm{~cm}^{-1}$ is corresponding to the $\mathrm{P}=\mathrm{O}$ absorption band of $\mathrm{DDP}$ and the peaks at $1057 \mathrm{~cm}^{-1}$ and at $974 \mathrm{~cm}^{-1}$ are due to the $\mathrm{P}-\mathrm{O}-\mathrm{C}$ absorption of DDP. ${ }^{23,29}$ The appearance of these peaks demonstrates that DDP has been incorporated into PA6 chain by the copolymerization reaction.

In order to confirm the above conclusion, ${ }^{1} \mathrm{H}$-NMR spectra of FRPA6-5 (deuterosulfuric acid as solvent) was conducted and the resultant spectrum has been shown in Fig. 3. It could be observed that the chemical shifts at 1.76 (a) ppm, 2.08 (b) ppm, 3.04 (c) ppm and 3.85 (d) ppm are corresponding to $\mathrm{H}$ on PA6. The peaks at 7.64-8.53 (e) ppm, 3.48 (g) ppm, 3.24 (h) ppm and 1.62 (f) ppm account for the chemical shifts of $\mathrm{H}$ on the diphenyl and methylene of DDP. To further confirm the chemical structure, ${ }^{31} \mathrm{P}-\mathrm{NMR}$ spectra of DDP (deuterated DMSO as solvent) and FRPA6-5 were observed and shown in Fig. 4. It is found that the P proton signals of DDP appeared at 36.59 and $36.03 \mathrm{ppm}$. This is in good agreement with the ${ }^{31} \mathrm{P}-\mathrm{NMR}$ spectra reported by Zhang C. et al. ${ }^{34}$ Similar P proton signals at 46.54 and 47.19 ppm were also observed in FRPA6-5. This is in good agreement with the ${ }^{31} \mathrm{P}-\mathrm{NMR}$ spectra reported by Wei $\mathrm{Z}$. Y.

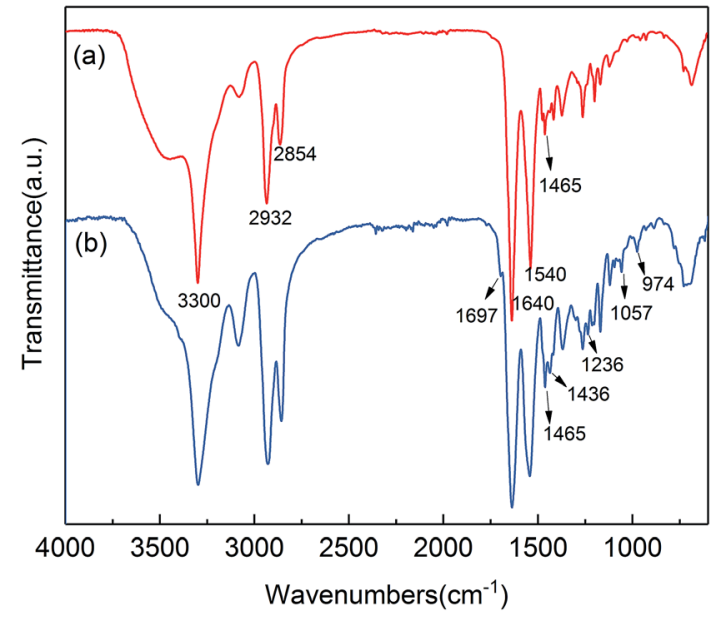

Fig. 2 FTIR spectra of PA6 (a) and FRPA6 (b). 


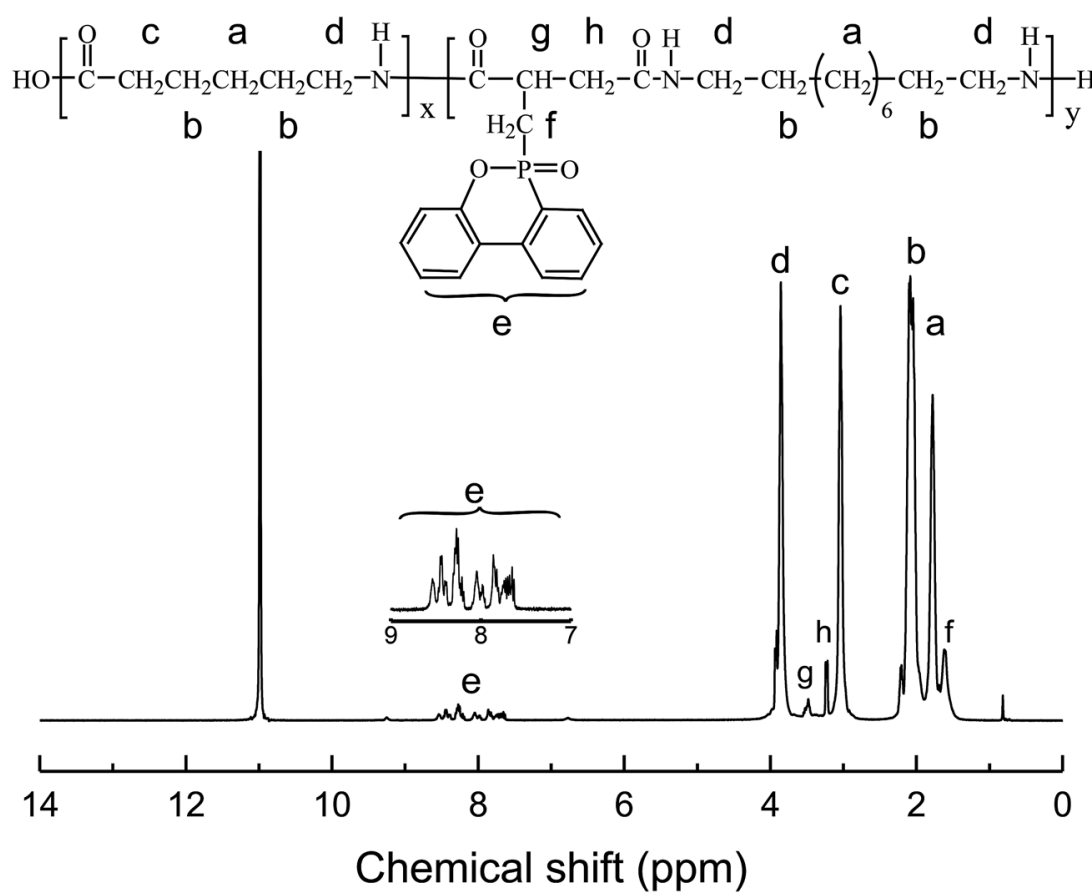

Fig. $3{ }^{1} \mathrm{H}-\mathrm{NMR}$ spectrum of FRPA6-5.

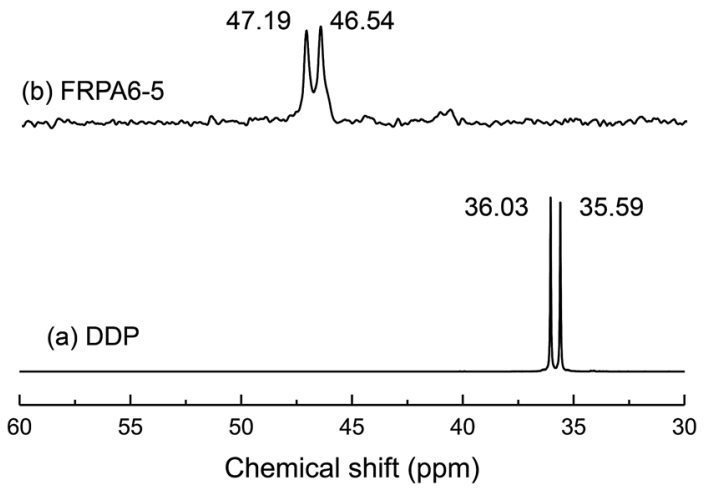

Fig. $4{ }^{31}$ P-NMR spectra of DDP (a) and FRPA6-5 (b).

et al. ${ }^{25,35}$ Therefore, these results along with the observations from FTIR (Fig. 2) concluded that DDP has been incorporated into PA6.

3.1.2. Molecular weight and molecular weight distribution. The molecular weight and the molecular weight distribution of PA6 and FRPA6 have been shown in Table 1, where $M_{\eta}, M_{\mathrm{n}}$ and PD referred to the viscosity-average molecular weight, number-

Table 1 Molecular weight of PA6 and FRPA6

\begin{tabular}{llll}
\hline Sample & $M_{\eta}\left(\mathrm{g} \mathrm{mol}^{-1}\right)$ & $M_{\mathrm{n}}\left(\mathrm{g} \mathrm{mol}^{-1}\right)$ & PD \\
\hline PA6 & $1.75 \times 10^{4}$ & $2.19 \times 10^{4}$ & 1.76 \\
FRPA6-2 & $1.64 \times 10^{4}$ & $2.05 \times 10^{4}$ & 1.93 \\
FRPA6-3 & $1.46 \times 10^{4}$ & $1.82 \times 10^{4}$ & 2.62 \\
FRPA6-4 & $1.29 \times 10^{4}$ & $1.60 \times 10^{4}$ & 2.87 \\
FRPA6-5 & $1.22 \times 10^{4}$ & $1.51 \times 10^{4}$ & 3.12
\end{tabular}

average molecular weight and the molecular weight distribution respectively. It can be seen that with the loading of flame retardant, the molecular weight decreased and the molecular weight distribution broadened. There are two probable reasons that could be accounted for the reduction of average molecular weight. On the one hand, the incorporation of DDP with benzene ring hinders the condensation polymerization between the polyamide chains. On the other hand, the activity of reactive groups on the flame retardant is affected by the linking of bulky side-groups, which can subsequently reduce the reactivity of end-groups and hinder further propagation. ${ }^{35}$ Irrespective of this, the viscosity of FRPA6 is still able to meet the requirements of processing and spinning.

3.1.3. Thermal properties. DSC measurements were carried out to study the thermal transitions and crystallinity of PA6 and FRPA6. DSC curves of the samples for melting and crystallization are shown in Fig. 5. The related crystallization temperature $\left(T_{\mathrm{c}}\right)$, melting temperature $\left(T_{\mathrm{m}}\right)$, fusion enthalpy $\left(\Delta H_{\mathrm{m}}\right)$ and $X_{\mathrm{c}}$ are summarized in Table 2. It was observed that the $T_{\mathrm{m}}$ of FRPA6 decreased as the content of DDP increased. This phenomenon was due to the symmetry and regularity of PA6 chain was destroyed by the rigid biphenyl structure of DDP. In the crystallization curves, the value of $T_{\mathrm{c}}$ was also found to shift to lower temperature with an increase in the content of DDP. This could be attributed to the rigid biphenyl structure of DDP, which restrained FRPA6 to crystallize at high temperatures. In addition, the $X_{\mathrm{c}}$ reduced from $37.59 \%$ for PA6 to $28.19 \%$ for FRPA6 containing $5 \mathrm{wt} \%$ DDP. This could be explained as follows. At first, since DDP is introduced into the molecular chain of PA6, it would break the regularity of main chain; secondly, the rigid and asymmetric steric chemical structure of DDP may restrict the mobility of molecular chain. Thus, the 

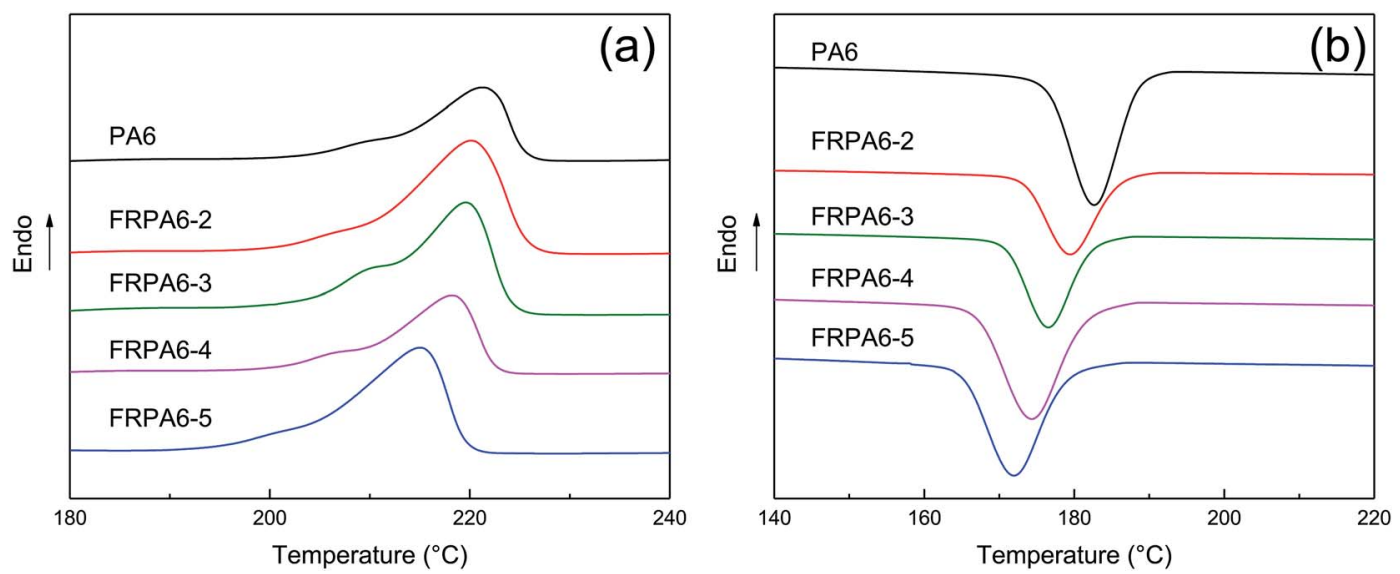

Fig. 5 DSC curves of PA6 and FRPA6 for melting (a) and crystallization (b).

Table 2 DSC heating and cooling results of PA6 and FRPA6

\begin{tabular}{lllll}
\hline Sample & $T_{\mathrm{m}}\left({ }^{\circ} \mathrm{C}\right)$ & $\Delta H_{\mathrm{m}}\left(\mathrm{J} \mathrm{g}^{-1}\right)$ & $T_{\mathrm{c}}\left({ }^{\circ} \mathrm{C}\right)$ & $X_{\mathrm{c}}(\%)$ \\
\hline PA6 & 221.29 & 71.65 & 182.66 & 37.59 \\
FRPA6-2 & 220.05 & 68.24 & 179.44 & 35.80 \\
FRPA6-3 & 219.57 & 65.59 & 177.18 & 34.41 \\
FRPA6-4 & 218.31 & 64.43 & 174.31 & 33.80 \\
FRPA6-5 & 215.03 & 53.73 & 172.95 & 28.19
\end{tabular}

crystallization of FRPA6 is more incomplete with a higher content of DDP. Different from the additive flame retardant added in PA6 which is playing a role of heterogeneous nucleation, DDP hindered the molecular chain movement of PA6 due to the steric effect. ${ }^{25,26}$ As a result, the crystallization temperature and crystallinity degree decreased.

Thermogravimetric analysis is an effective tool usually used to study the thermal stability of various polymers. The thermal degradation behavior of all the samples under air atmosphere is presented in Fig. 6. The temperature for the onset degradation, the temperature at which 50\% degradation and the temperature at which maximum decomposition (labelled as $T_{5 \%}, T_{50 \%}$ and

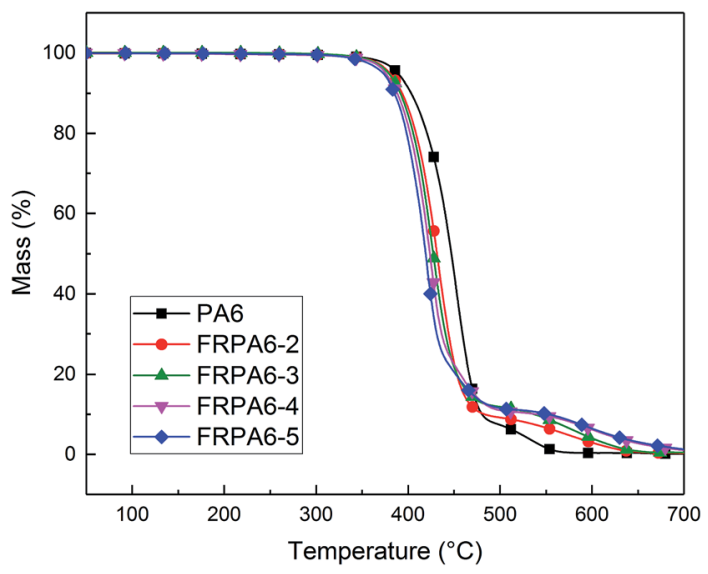

Fig. 6 Thermogravimetry curves of PA6 and FRPA6.
$\left.T_{\max }\right)$, and the char yield at 600 and $700{ }^{\circ} \mathrm{C}$ are summarized in Table 3. It could be noted from the TG curve that at the initial period, the $T_{5 \%}$ and $T_{\max }$ of FRPA6 were lower than neat PA6. This indicates the introduction of flame retardant causing the reduction of thermal stability of FRPA6. The $T_{5 \%}$ and $T_{\max }$ of neat PA6 are $388.46{ }^{\circ} \mathrm{C}$ and $452.48{ }^{\circ} \mathrm{C}$, respectively. However, the introduction of DDP reduced the $T_{5 \%}$ to $372.42{ }^{\circ} \mathrm{C}$ for FRPA6-5, which was due to the degradation of $\mathrm{P}-\mathrm{C}$ bond in the flame retardant. The bond energy of $\mathrm{P}-\mathrm{C}$ bond is lower than others in FRPA6 and $\mathrm{P}-\mathrm{C}$ bond is easier to break at the same temperature. In addition, $T_{\max }$ of FRPA6 samples were lower than PA6 which may be ascribed to the degradation of $\mathrm{P}-\mathrm{C}$ bond which in turn accelerates the cross-linking of PA6 to a considerable degree. ${ }^{24,36-38}$ In contrast, FRPA6 exhibited better thermal stability than PA6 when the temperature increased to $470{ }^{\circ} \mathrm{C}$. FRPA6-5 increased the char residue of PA6 from 0.34 to $6.43 \%$ at $600{ }^{\circ} \mathrm{C}$ thereby showing a better thermal oxidative stability. These results indicate that adding a certain amount of DDP can significantly improve the yield of protective char layer. The char layer in turn prevents the transfer of heat and oxygen and prevents the thermal decomposition of potential substances. Therefore, the introduction of DDP could improve the flame retardant performance of FRPA6 by promoting the formation of char layer.

3.1.4. Mechanical property. The mechanical property of PA6 and FRPA6 samples has been shown in Fig. 7. Compared to PA6, the tensile strength and the elongation at break of FRPA6 resins were reduced with the incorporation of DDP. The tensile

Table 3 Main thermogravimetry data of samples under air atmosphere

\begin{tabular}{llllll}
\hline Sample & $T_{5 \%}\left({ }^{\circ} \mathrm{C}\right)$ & $T_{50 \%}\left({ }^{\circ} \mathrm{C}\right)$ & $T_{\max }\left({ }^{\circ} \mathrm{C}\right)$ & $\begin{array}{l}\text { Char residue } \\
\text { at } 600{ }^{\circ} \mathrm{C}(\%)\end{array}$ & $\begin{array}{l}\text { Char residue } \\
\text { at } 700{ }^{\circ} \mathrm{C}(\%)\end{array}$ \\
\hline PA6 & 388.46 & 447.06 & 452.48 & 0.34 & 0.11 \\
FRPA6-2 & 379.73 & 431.33 & 430.64 & 2.96 & 0.35 \\
FRPA6-3 & 378.53 & 427.14 & 428.75 & 4.03 & 0.47 \\
FRPA6-4 & 375.06 & 423.56 & 422.38 & 5.87 & 1.03 \\
FRPA6-5 & 372.42 & 419.19 & 419.77 & 6.43 & 1.25
\end{tabular}




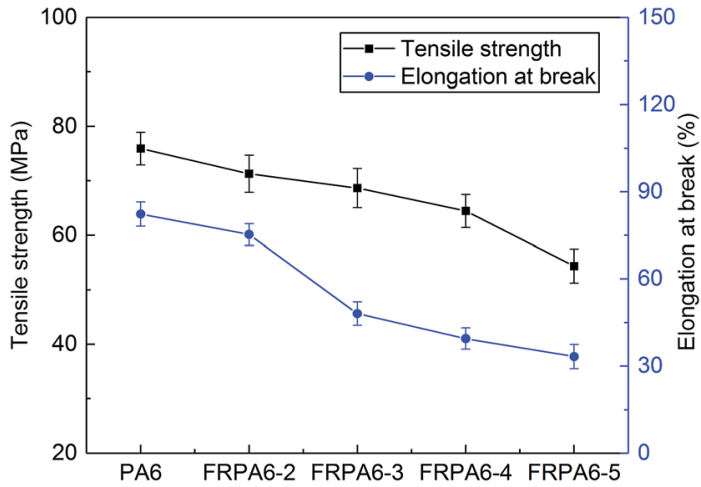

Fig. 7 Mechanical property of PA6 and FRPA6.

Table 4 Vertical burning test results and LOI values of PA6 and FRPA6 Vertical burning test

\begin{tabular}{lllll} 
Sample & Melt drippings & $\begin{array}{l}\text { Ignite cotton } \\
\text { or not }\end{array}$ & Rating & $\begin{array}{l}\text { LOI value } \\
(\%)\end{array}$ \\
\hline PA6 & Serious & Yes & V-2 & $23.5 \pm 0.2$ \\
FRPA6-2 & Some & Yes & V-2 & $25.1 \pm 0.1$ \\
FRPA6-3 & Some & Yes & V-2 & $28.4 \pm 0.1$ \\
FRPA6-4 & A little & No & V-0 & $31.6 \pm 0.2$ \\
FRPA6-5 & Little & No & V-0 & $33.7 \pm 0.2$ \\
& & & & \\
\hline
\end{tabular}

strength of PA6 was 75.9 MPa, and the tensile strength of FRPA6-5 was 54.3 MPa which was $28.46 \%$ lower than PA6. The elongation at break of PA6 was $82.3 \%$, and the elongation at break of FRPA6-5 was $33.2 \%$ which was $59.66 \%$ lower than PA6. The introduction of flame retardant reduced the molecular weight and crystallinity degree of FRPA6, which are related to the mechanism properties of polymeric materials, thus the mechanical property of resins decreased.

3.1.5. Flame retardant properties. The vertical burning test and LOI test are used to estimate the flammability of materials. The results of vertical burning test and LOI values of PA6 and FRPA6 are summarized in Table 4. Due to the absorbent cotton was ignited by the heavy burning drippings during test, the UL 94 rating of PA6 belongs to V-2 (Fig. S1†). The flame retardant performance of FRPA6 improved significantly with the introduction of DDP. FRPA6 containing $4 \mathrm{wt} \%$ DDP could achieve a V-0 rating when the materials are extinguished after ignition and the absorbent cotton is not burnt. The sample shows a little melt dripping during test and self-extinguishing rapidly even if the melt dripping falls. It can also be observed that with the loading of flame retardant, the LOI value has improved significantly. The LOI value increased from $23.5 \%$ for PA6 to $33.7 \%$ for FRPA6-5 which indicates that the DDP is an effective flame retardant for PA6.

In order to predict the combustion performance of samples under fire conditions, cone calorimetry was selected due to its good correction with real fire disasters. ${ }^{37}$ Flammability parameters such as the time to ignition (TTI), flame out time (FOT), total heat release (THR), heat release rate (HRR), effective heat combustion (EHC), specific extinction area (SEA) and char residue could be extracted from cone calorimetry results.

The peak of heat release rate (p-HRR) and THR are two important parameters to evaluate the fire disaster. The HRR and THR curves of PA6 and FRPA6-5 have been plotted in Fig. 8 and the corresponding data are summarized in Table 5 . The ignitability of samples was assessed by TTI. It was observed that TTI of FRPA6-5 was a little lower than PA6, indicating that the introduction of flame retardant did not influence the thermal
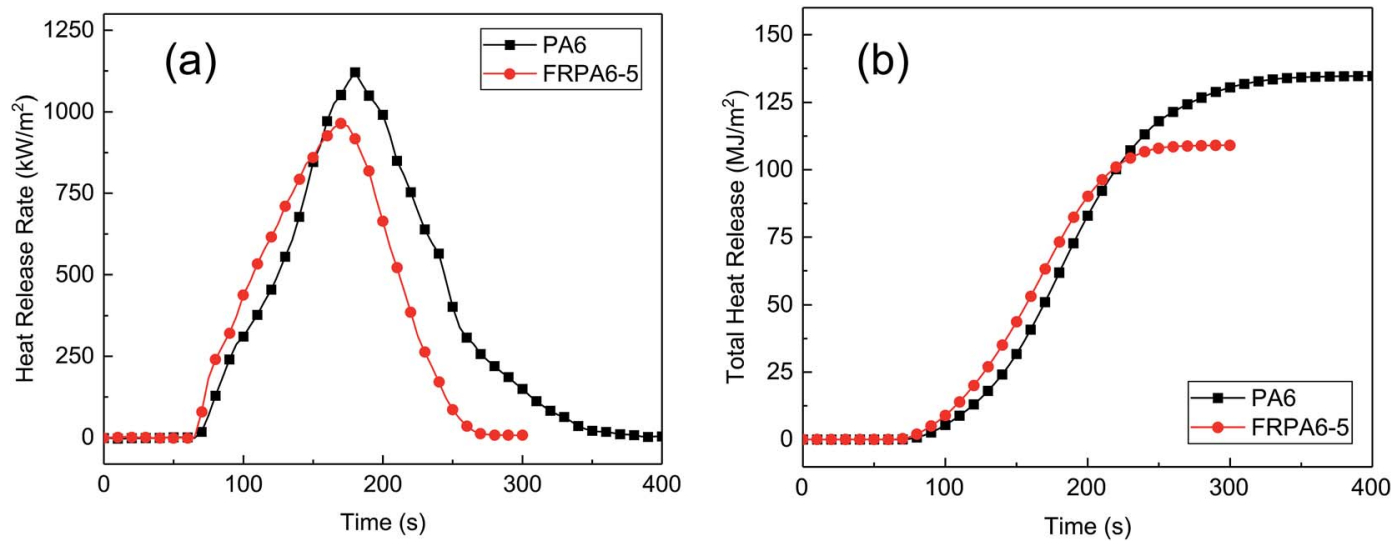

Fig. 8 HRR curves (a) and thr curves (b) of PA6 and FRPA6-5.

Table 5 Cone calorimetric data with a heat flux of $50 \mathrm{~kW} \mathrm{~m}^{-2}$

\begin{tabular}{lccccccc}
\hline Sample & TTI $(\mathrm{s})$ & FOT $(\mathrm{s})$ & p-HRR $\left(\mathrm{kW} \mathrm{m}^{-2}\right)$ & THR $\left(\mathrm{MJ} \mathrm{m}^{-2}\right)$ & EHC $\left(\mathrm{MJ} \mathrm{kg}^{-1}\right)$ & ${\text { SEA }\left(\mathrm{m}^{2} \mathrm{~kg}^{-1}\right)}_{\text {Char residue }(\%)}$ \\
\hline PA6 & $63 \pm 1$ & $374 \pm 5$ & $1120 \pm 25$ & $135 \pm 2$ & $37 \pm 0.3$ & $202 \pm 12$ & $0.17 \pm 0.1$ \\
FRPA6-5 & $60 \pm 1$ & $262 \pm 3$ & $964 \pm 20$ & $102 \pm 1$ & $29 \pm 0.3$ & $321 \pm 10$
\end{tabular}


stability of FRPA6 at high temperature. The FRPA6 had a lower FOT value indicating a short burning time and a lower risk of secondary ignition. The p-HRR of PA6 was $1120 \mathrm{~kW} \mathrm{~m}^{-2}$ and the p-HRR of FRPA6-5 was $964 \mathrm{~kW} \mathrm{~m}^{-2}$ which was decreased by $13.93 \%$ as compared to PA6. The THR of PA6 was $135 \mathrm{MJ} \mathrm{m}^{-2}$, whereas the THR of FRPA6-5 was $102 \mathrm{MJ} \mathrm{m}^{-2}$ which was decreased by $24.44 \%$ as compared to PA6. It was observed that the char residue of FRPA6 increased from $0.17 \%$ to $1.25 \%$ as compared to PA6. The char layer on the surface acted as a barrier and protected the matrix polymer from heating in the condensed phase. It is worth to note that the EHC of FRPA6-5 decreased by $21.62 \%$ as compared to PA6; and the SEA of FRPA6-5 increased by $58.91 \%$ as compared to that of PA6. The EHC reflects the combustion of volatile gases in the meteorological flame. The SEA refers to smoke produced by the volatile unit mass. The higher SEA and lower EHC indicate the existence of noncombustible gas which played a role in the gas phase. DDP, as one of the DOPO derivatives, is known to act as a gasphase mechanism with the formation of $\mathrm{PO}^{*}$ radicals. DDP promoted the formation of phosphorus-rich char and the char layers protected the underlying resin. ${ }^{39}$ Consequently, the improved flame retardant performance of FRPA6 can be attributed to the combined action of flame retardant mechanism in the condensed phase and gas phase.

The morphology and chemical composition of char residue are closely related to flame retardant process. The char residues of PA6 and FRPA6-5 were obtained by heating the samples to $600{ }^{\circ} \mathrm{C}$ for $20 \mathrm{~min}$ in a muffle furnace. The morphologies of char residue for PA6 and FRPA6-5 were obtained by SEM (Fig. 9). It can be observed that the surface of PA6 is full of holes and the structure of holes is open and extensive. These holes were formed by gaseous decomposition products (such as caprolactam) from PA6 diffuse through the char layer. As a result, the char residue of PA6 was poor and cannot prevent the transfer of heat, oxygen and combustible gases. In contrast, the surface of FRPA6 was compact and tight, indicating a dense and continuous char layer structure. The char layer could protect the matrix polymer from heat and against the transfer of oxygen and combustible gases. Besides, it can be observed that FRPA6 formed a layer of continuously and consolidated char of lots of small microspheres.

The selected area of the energy dispersive spectroscopy (EDS) analysis from the SEM images supports the generation of char in the samples. Compared to PA6, the phosphorus element of the residue of FRPA6-5 increased to $14.93 \%$. An increase in the amount of phosphorus could produce many phosphoruscontaining free radicals, which in turn combine with the segmental radicals generated from the heterolytic cleavage of PA6 to form a compact char layer. During burning, the phosphorus in FRPA6 is converted to phosphoric acid and a further thermal decomposition leads to the formation of polyphosphoric acid. ${ }^{40}$ The polyphosphoric acid esterifies and dehydrates the pyrolyzing polymer and a simultaneously forming phosphorus-rich carbonaceous layer further inhibits the pyrolysis reactions. Further support comes from EDS analysis which showing the $\mathrm{C}$ and $\mathrm{H}$ percentages of residual char. It could be found that FRPA6 has similar C (82.01\%) but lower O content $(3.06 \%)$ as compared to PA6 (83.29\% C and $16.71 \% \mathrm{O})$. The flame retardance of corresponding materials can be assessed from the $\mathrm{O}$ content of residual char. The lower percentage of $\mathrm{O}$ of the residual char of FRPA6 implying that the oxidation reaction greatly decreased with an imperfect combustion, which is likely related to the barrier effect of the char layer of FRPA6. Consequently, the introduction of DDP changed the degradation pathway of FRPA6 and improved the flame retardant performance of FRPA6.

\subsection{Properties of flame retardant polyamide 6 fibre}

3.2.1. Morphology analysis. The SEM images of the surface and cross-section of PA6 fibre and FRPA6-5 fibre were shown in Fig. 10. Both of the surfaces of PA6 fibre (a, $\left.a^{\prime}\right)$ and FRPA6-5 fibre $\left(c, c^{\prime}\right)$ were relativity smooth, no flame retardant shown in the surface of FRPA6-5 fibre. In the large view of cross-section, there were almost no holes or defects in PA6 fibre ( $\left.b^{\prime}\right)$ and FRPA6-5
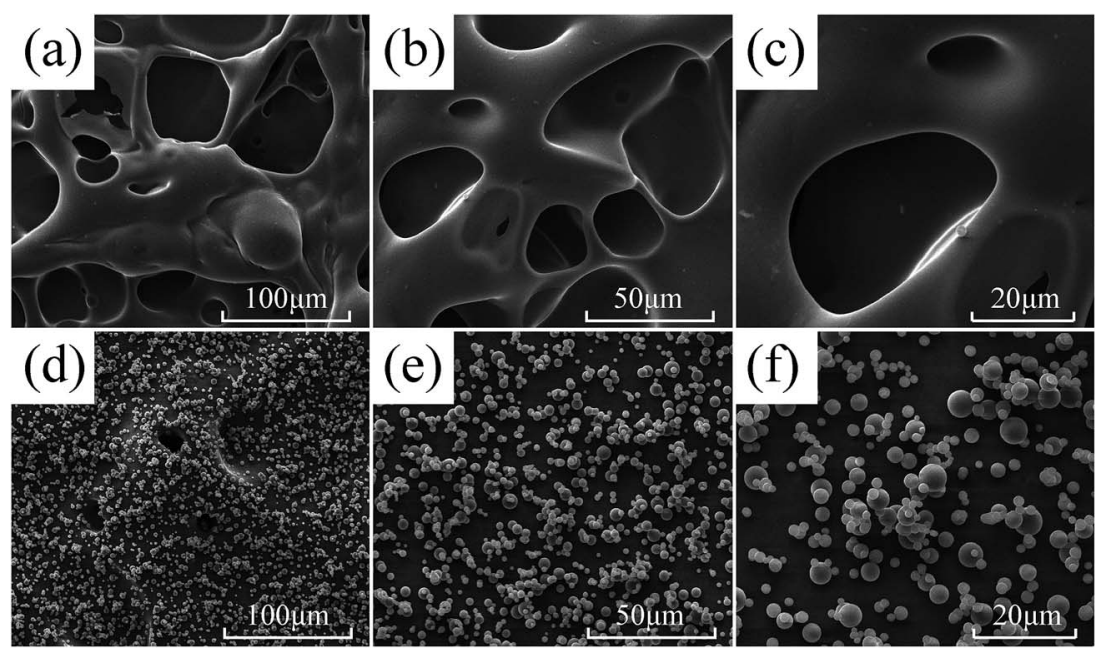

Fig. 9 SEM images of char residue for PA6 $(a, b, c)$ and FRPA6 (d, e, f). 

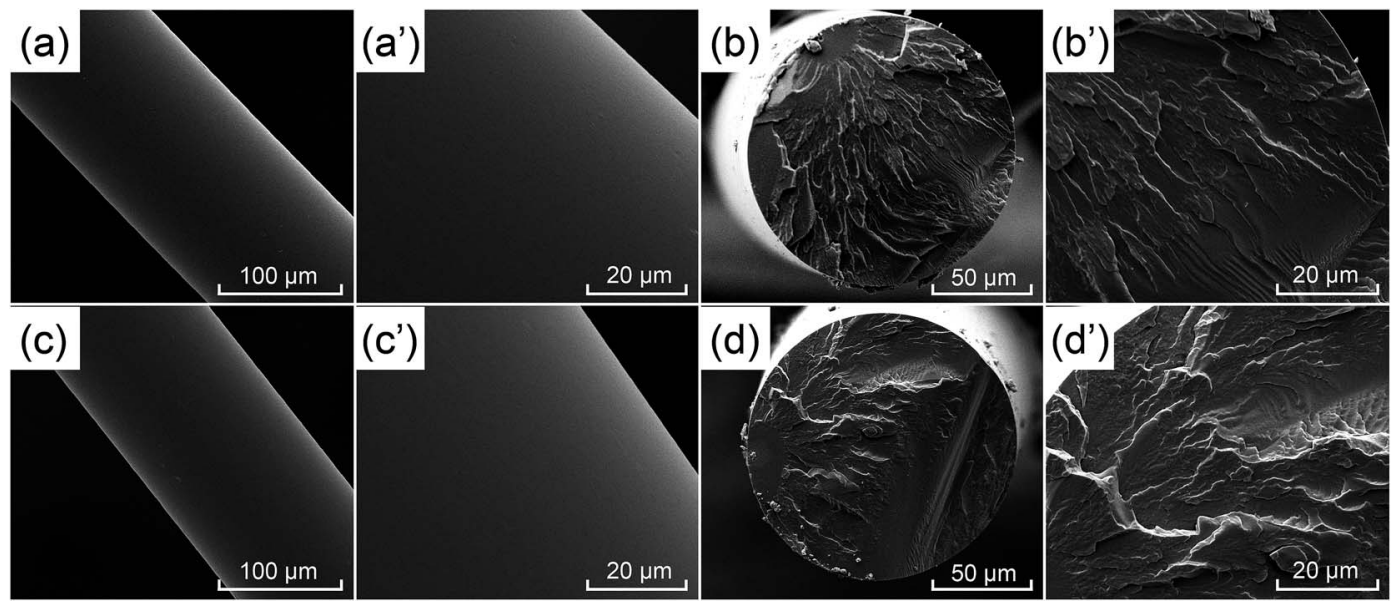

Fig. 10 SEM images of the surface and cross-section of PA6 fibre $\left(a, a^{\prime}, b, b^{\prime}\right)$ and FRPA6-5 fibre $\left(c, c^{\prime}, d, d^{\prime}\right)$.

fibre $\left(\mathrm{d}^{\prime}\right)$. This is because DDP were introduced into PA6 molecular chain by chemical bonding. In order to reveal the presence of element $P$, which was the representative element of DDP, EDS mapping was conducted on the surface of FRPA6-5 fibre and shown in Fig. 11. The results obtained by SEM-EDS indicating the presence of FRPA6-5 fibre with different elemental composition. In the clusters presented in Fig. 10, element $\mathrm{C}, \mathrm{O}, \mathrm{P}$ and $\mathrm{N}$ were detected. And the distribution of the element C (68.42\%), O (15.80\%), P (0.23\%) and $\mathrm{N}(15.54 \%)$ on the surface of FRPA6-5 fibre is uniform. The elemental compositions of FRPA6-5 fibre confirmed the incorporation of DDP in FRPA6-5 fibre.

3.2.2. Thermal properties. In order to study the thermal property of fibre after drafting, DSC measurement was carried out. DSC heating curves of PA6 fibre and FRPA6 fibres were shown in Fig. 12 and the DSC results were shown in Table 6. It is observed that both of the $T_{\mathrm{m}}$ and $X_{\mathrm{c}}$ of PA6 fibre and FRPA6 fibres are a little higher than that of PA6 resin and FRPA6 resins presented in Table 2. The $T_{\mathrm{m}}$ of PA6 fibre and FRPA6-5 fibre increased to $223.24{ }^{\circ} \mathrm{C}$ and $216.06{ }^{\circ} \mathrm{C}$ respectively. The $X_{\mathrm{c}}$ of PA6

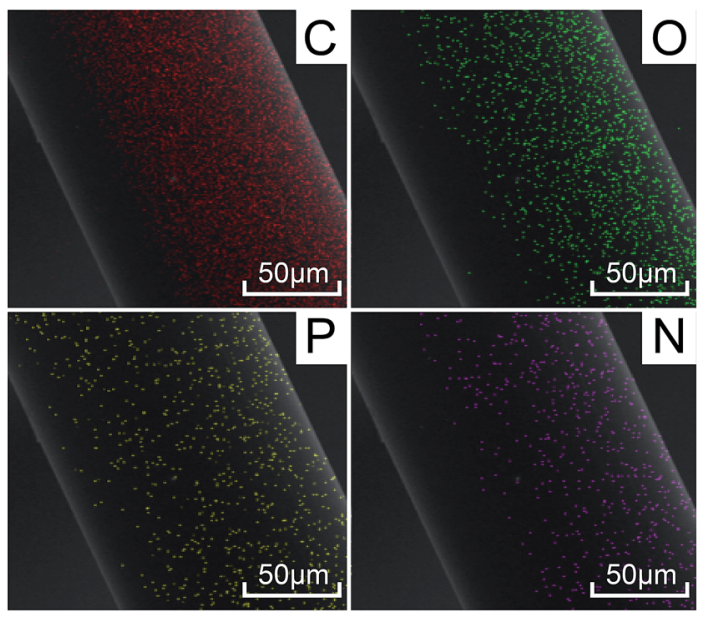

Fig. 11 SEM-EDS mapping of FRPA6-5 fibre.

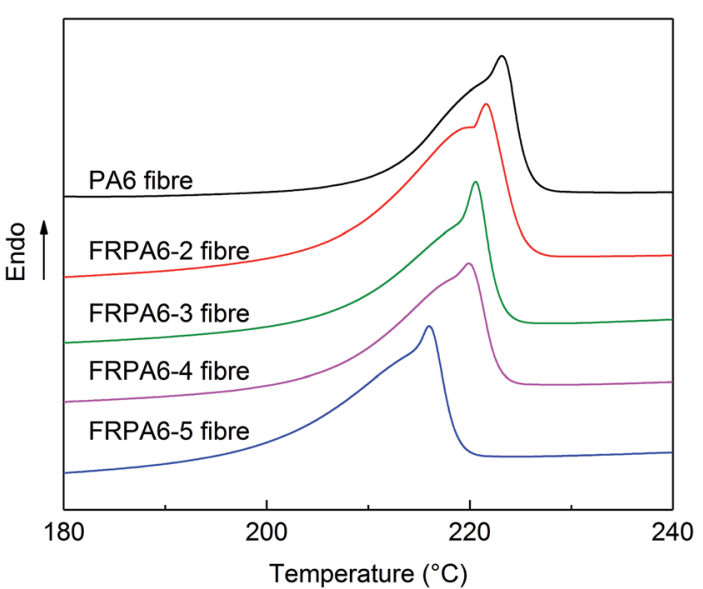

Fig. 12 DSC heating curves of PA6 fibre and FRPA6 fibre.

fibre and FRPA6-5 fibre increased to $38.75 \%$ and $30.65 \%$ respectively. In addition, the melting peaks of the fibres are sharper than those of the resins. This can be explained as follows. For polyamide, a crystalline polymer, stretching is beneficial to crystallization, resulting in the improvement of melting point and crystallinity.

3.2.3. Mechanical property and orientation test. The mechanical property and orientation test results of PA6 fibre and FRPA6 fibres have been shown in Table 7. The orientation degree of fibre is represented by orientation factor " $f$ ", which reflects the propagation aeolotropism of acoustic wave caused

Table 6 DSC heating results of PA6 fibre and FRPA6 fibres

\begin{tabular}{llll}
\hline Sample & $T_{\mathrm{m}}\left({ }^{\circ} \mathrm{C}\right)$ & $\Delta H_{\mathrm{m}}\left(\mathrm{J} \mathrm{g}^{-1}\right)$ & $X_{\mathrm{c}}(\%)$ \\
\hline PA6 fibre & 223.24 & 73.85 & 38.75 \\
FRPA6-2 fibre & 221.65 & 70.41 & 36.94 \\
FRPA6-3 fibre & 220.59 & 68.53 & 35.95 \\
FRPA6-4 fibre & 219.95 & 67.56 & 35.46 \\
FRPA6-5 fibre & 216.06 & 58.42 & 30.65
\end{tabular}


Table 7 Mechanical and orientation test results of PA6 fibre and FRPA6 fibres

\begin{tabular}{lllll}
\hline & $\begin{array}{l}\text { Tenacity } \\
\text { at break } \\
\left(\mathrm{cN} \mathrm{dtex}^{-1}\right)\end{array}$ & $\begin{array}{l}\text { Elongation } \\
\text { at break }(\%)\end{array}$ & $\begin{array}{l}\text { Sound } \\
\text { velocity } \\
\left(\mathrm{km} \mathrm{s}^{-1}\right)\end{array}$ & $\begin{array}{l}\text { Orientation } \\
\text { factor }\end{array}$ \\
\hline PA6 fibre & 4.3 & 57.8 & 2.26 & 0.65 \\
FRPA6-2 fibre & 3.8 & 55.2 & 2.27 & 0.65 \\
FRPA6-3 fibre & 3.5 & 51.9 & 2.27 & 0.65 \\
FRPA6-4 fibre & 3.1 & 48.3 & 2.25 & 0.65 \\
FRPA6-5 fibre & 3.0 & 45.2 & 2.24 & 0.64 \\
\hline
\end{tabular}

by orientation of the molecular chain. The tenacity at break of PA6 fibre was $4.3 \mathrm{cN} \mathrm{dtex}{ }^{-1}$, and the tenacity at break of FRPA6-5 fibre was $3.0 \mathrm{cN} \mathrm{dtex}{ }^{-1}$ which was $30.2 \%$ lower than PA6 fibre. It can be observed that the tenacity at break of FRPA6 decreased with the incorporation of DDP, but it still met the requirements of textiles (Fig. S2 $\dagger$ ). Interestingly, the sound velocity and orientation factor of FRPA6 fibres were similarly to that of PA6 fibre. This is because DDP is incorporated in the molecular chain of polyamide, different from the flame retardant fibre prepared with the additive type flame retardant which distributed between the separate molecule chains. ${ }^{26}$ Propagation speed of sound in the FRPA6 fibre is not affected by the physical additives. Therefore, the sound velocity of FRPA6 fibre was affected barely.

3.2.4. Flame retardant properties of fabric. Vertical burning test and LOI tests were carried out to evaluate the flame retardancy of fabric. The data were presented in Table 8 . Compared with the resin, fabric is very thin and it has large surface area, which can contact with oxygen more fully, so it is easier to be ignited and resulting in melt drippings with flame. Thus, it is more difficult to improve the flame retardant of fabric. In the vertical burning test, PA6 fabric showed poor flame resistance, as it burned rapidly after the ignition and the absorbent cotton were ignited by melt drippings. It may cause secondary fire and further damage. With the increase of flame retardant, both of the afterflame time and damaged length of FRPA6 fabric are shorter than that of PA6 fabric. FRPA6-5 fabric still has one melt dripping, but the melt dripping with no flame and didn't ignite the absorbent cotton (Fig. S3†). It is observed that the LOI value of FRPA6 fabric increased with the content of flame retardant. The higher content of DDP, the higher LOI value of fabric. The LOI value increased from $22.1 \%$ for PA6

Table 8 Vertical burning test and LOI results of the fabric samples

\begin{tabular}{llllll}
\hline & & \multicolumn{5}{c}{$\begin{array}{l}\text { Damaged } \\
\text { Afterflame } \\
\text { Sample }\end{array}$} & $\begin{array}{l}\text { Afterglow } \\
\text { time }(\mathrm{s})\end{array}$ & $\begin{array}{l}\text { Ignith } \\
\text { time } \\
\text { cotton }\end{array}$ & $\begin{array}{l}\text { LOI } \\
\text { or not }\end{array}$ & value (\%) \\
\hline PA6 fabric & 5.3 & 0 & 12.3 & Yes & $22.1 \pm 0.2$ \\
FRPA6-2 fabric & 4.7 & 0 & 7.4 & Yes & $23.7 \pm 0.2$ \\
FRPA6-3 fabric & 2.3 & 0 & 6.2 & Yes & $25.8 \pm 0.1$ \\
FRPA6-4 fabric & 2.1 & 0 & 6.1 & Yes & $27.1 \pm 0.2$ \\
FRPA6-5 fabric & 1.7 & 0 & 5.2 & No & $28.4 \pm 0.2$
\end{tabular}

fabric to $28.4 \%$ for FRPA6-5 fabric. These results showed that the flame retardancy of FRPA6 fabric was definitely improved by the introduction of DDP.

\section{Conclusions}

In this study, FRPA6 resins were prepared by introducing DDP as a flame retardant during the polymerization of caprolactam, following which the FRPA6 fibres were produced by melt spinning. The crystallization and thermal stability of FRPA6 were decreased by the introduction of DDP. Whereas, the flame retardant performance of samples improved with the loading of flame retardant. The tensile strength of FRPA6 containing $5 \mathrm{wt} \%$ flame retardant was $54.3 \mathrm{MPa}$, and it achieved a V0 rating according to UL 94 criterion with an LOI value of $33.7 \%$. The char layer acted as a fire barrier in the condensed phase, and the higher gas production and lower effective heat of combustion indicated that the noncombustible gas acted in the gas phase. The spinnability of FRPA6 was observed to be good and the tenacity at break of FRPA6 fibres reached to $3.0 \mathrm{cN}$ $\mathrm{dtex}^{-1}$ which met the requirements of textiles. The flame retardancy of FRPA6 fibre was definitely improved and the LOI value of FRPA6-5 fabric could reach $28.4 \%$, and thereby showing a better prospect in its application.

\section{Conflicts of interest}

The authors declare no competing financial interest.

\section{Acknowledgements}

This study was supported by the National Key Research and Development Program of China (No. 2017YFB0309003), National Natural Science Foundation of China (No. 21374015), Program of Introducing Talents of Discipline to Universities (No. 111-2-04).

\section{References}

1 L. Sang, C. Wang, Y. Wang and Z. Wei, RSC Adv., 2017, 7, 43334-43344.

2 G. Zhang, Y. X. Zhou, Y. Li, X. J. Wang, S. R. Long and J. Yang, RSC Adv., 2015, 5, 49958-49967.

3 Y. Bai, L. Huang, T. Huang, J. Long and Y. Zhou, Polymer, 2013, 54, 4171-4176.

4 C. Q. Yang and Q. L. He, J. Anal. Appl. Pyrolysis, 2011, 91, 125133.

5 W. Wei, X. L. Wang, Z. W. Liu, D. R. Wu, L. Qiu, F. C. Tsai, Y. C. Lai, P. Zhu and J. T. Yeh, Polym. Eng. Sci., 2011, 51, 755-763.

6 W. He, H. Zhu, Y. Xiang, L. Long, S. Qin and J. Yu, Polym. Degrad. Stab., 2017, 144, 442-453.

7 M. Zhao, D. Yi, G. Camino, A. Frache and R. Yang, RSC Adv., 2017, 7, 861-869.

8 J. Cai, A. Wirasaputra, Y. Zhu, S. Liu, Y. Zhou, C. Zhang and J. Zhao, RSC Adv., 2017, 7, 19593-19603. 
9 S. V. Levchik, E. D. Weil and M. Lewin, Polym. Int., 1999, 48, 532-557.

10 A. R. Horrocks, B. K. Kandola, P. J. Davies, S. Zhang and S. A. Padbury, Polym. Degrad. Stab., 2005, 88, 3-12.

11 R. Horrocks, A. Sitpalan, C. Zhou and B. Kandola, Polymers, 2016, 8, 288.

12 G. Camino, L. Costa and G. Martinasso, Polym. Degrad. Stab., 1989, 23, 359-376.

13 S. V. Levchik and E. D. Weil, J. Fire Sci., 2006, 24, 345-364.

14 L. Chen and Y. Z. Wang, Polym. Adv. Technol., 2010, 21, 1-26.

15 W. Lyu, Y. Cui, X. Zhang, J. Yuan and W. Zhang, Fire Mater., 2017, 41, 349-361.

$16 \mathrm{~J}$. Asrar, Polymer-bound non-halogen fire resistant compositions, US Pat., 5750603, 1998.

17 X. F. Yang, Q. L. Li, Z. P. Chen and H. L. Han, Bull. Mater. Sci., 2009, 32, 375-380.

18 A. Buczko, T. Stelzig, L. Bommer, D. Rentsch, M. Heneczkowski and S. Gaan, Polym. Degrad. Stab., 2014, 107, 158-165.

19 S. Y. Lu and I. Hamerton, Prog. Polym. Sci., 2002, 27, 16611712.

20 J. Li, H. F. Zhu, J. Li, X. Y. Fan and X. Y. Tian, J. Appl. Polym. Sci., 2011, 122, 1993-2003.

21 Y. Li, K. Liu, J. Zhang and R. Xiao, Polym. Adv. Technol., 2018, 29, 951-960.

22 S. J. Chang and F. C. Chang, J. Appl. Polym. Sci., 2015, 72, 109-122.

23 L. S. Wang, H. B. Kang, S. B. Wang, Y. Liu and R. Wang, Fluid Phase Equilib., 2007, 258, 99-107.

24 H. B. Chen, Y. Zhang, L. Chen, Z. B. Shao, Y. Liu and Y. Z. Wang, Ind. Eng. Chem. Res., 2010, 49, 7052-7059.

25 H. Ge, W. Wang, Y. Pan, X. J. Yu, W. Z. Hu and Y. Hu, RSC $A d v .$, 2016, 6, 81802-81808.
26 Y. Y. Li, Y. Z. Lin, K. Sha and R. Xiao, Text. Res. J., 2017, 87, 561-569.

27 I. Goitisolo, J. I. Eguiazábal and J. Nazábal, Polym. Degrad. Stab., 2008, 93, 1747-1752.

28 A. Šehić, B. Tomšič, I. Jerman, J. Vasiljević, J. Medved and B. Simončič, Polym. Degrad. Stab., 2016, 128, 245-252.

29 B. Schartel, A. I. Balabanovich, U. Braun, U. Knoll, J. Artner, M. Ciesielski, M. Döring, R. Perez, J. K. W. Sandler, V. Altstädt, T. Hoffmann and D. Pospiech, J. Appl. Polym. Sci., 2007, 104, 2260-2269.

30 W. Jiang, F. L. Jin and S. J. Park, J. Ind. Eng. Chem., 2015, 27, 40-43.

31 S. Tian, H. He, D. Wang, P. Yu, Y. Jia and Y. Luo, Fire Mater., 2017, 41, 983-992.

32 D. Zheng, J. Zhou, Y. Wang, F. Zhang and G. Zhang, Cellulose, 2018, 25, 787-797.

33 Q. Wu, J. P. Lü and B. J. Qu, Polym. Int., 2003, 52, 1326-1331. 34 C. Zhang, J. Y. Huang, S. M. Liu and J. Q. Zhao, Polym. Adv. Technol., 2011, 22, 1768-1777.

35 Z. Y. Wei, C. Zhou, Y. Yu and Y. Li, Polymer, 2015, 71, 31-42. 36 D. Bakirtzis, A. Ramani, J. Zhang and M. Delichatsios, Fire Saf. J., 2014, 69, 69-75.

37 J. Chen, S. Liu and J. Zhao, Polym. Degrad. Stab., 2011, 96, 1508-1515.

38 T. Kashiwagi, R. H. Harris, X. Zhang, R. M. Briber, B. H. Cipriano, S. R. Raghavan, W. H. Awad and J. R. Shields, Polymer, 2004, 45, 881-891.

39 M. L. Li, Y. H. Zhong, Z. Wang, A. Fischer, F. Ranft, D. Drummer and W. Wu, J. Appl. Polym. Sci., 2016, 133, 42932-42941.

40 B. Schartel, Materials, 2010, 3, 4710-4745. 